\title{
Gênero textual exposição oral na educação de jovens e adultos
}

\section{oral exposition textual genre in adult education}

Marcos Antônio Rocha Baltar*

Universidade Federal de Santa Catarina

Denise Ribas da Costa**

Universidade de Caxias do Sul

\begin{abstract}
RESUMO: Este artigo apresenta resultados do trabalho com o gênero textual Exposição Oral (EO) em uma turma da modalidade EJA - Ensino Médio de uma escola pública da cidade de Caxias do Sul. O propósito deste trabalho é auxiliar estudantes a ampliar seu repertório de gêneros de textos orais e subsidiar os professores a elaborar um trabalho didático-pedagógico sistematizado, sequência didática (SD), para a apropriação do gênero exposição oral. Também inserimos a exposição oral no conjunto de gêneros que podem ser trabalhados na implantação/ implementação de uma rádio escolar, proporcionando um desempenho satisfatório nesse ambiente discursivo. Este estudo integra a pesquisa-ação Midias e escola: letramentos e gêneros textuais e utiliza os dispositivos de problematização, ação, reflexão, ação, transformação.
\end{abstract}

PALAVRAS-CHAVE: Gênero textual; exposição oral; EJA; rádio escolar; sequência didática.

ABSTRACT: This article presents findings from a work with oral exposition genre in an adult education class in Caxias do Sul - RS, Brazil. Our purpose in this study is to help students to increase their oral genre repertoire and give support to teachers to elaborate a systematic pedagogical work, a Didactic Sequence, for the learning of oral exposition genre. We have also included oral exposition in the group of genres that can be studied for the implementation of a school radio in order to develop a good performance in that discursive sphere. This study is part of the action research project Medias and School: literacies and textual genres and follows the steps: action, problematization, reflection, action, and transformation.

KEYWORDS: Textual genre; oral exposition; adult education; school radio; didactic sequence.

*baltar@cpovo.net

**drcosta@ucs.br 


\section{Introdução}

O trabalho com os gêneros textuais orais, embora seja previsto pelos Parâmetros Curriculares Nacionais e em muitos outros documentos balizadores do ensino de Língua Portuguesa, ainda é muito incipiente em nosso país. Isso é visível quando analisamos periódicos especializados no tema, ou quando lemos anais de congressos da área de Letras - Linguística no Brasil.

Nesse artigo não estamos considerando gêneros orais e escritos como dicotômicos, mas como pertencentes a atividades de linguagem distintas da sociedade letrada, que se complementam no âmbito de um continuum, que vai do mais escrito ao menos escrito, do mais oral ao menos oral, de acordo com as condições de produção dos textos: o ambiente discursivo, a comunidade discursiva, os propósitos comunicativos dos escritores-leitores, falantes-ouvintes, entre outros fatores. Esse tema está explorado no Brasil, especialmente nos trabalhos de Kato (1987), Koch (1993), Marcuschi (2005), Schneuwly (1997), Schneuwly e Dolz (2004). Baltar (2009) sugere o trabalho com a Exposição Oral (doravante EO) tanto como um gênero de texto de sala de aula quanto como um gênero de texto que pode figurar em um quadro qualquer de um programa da rádio da escola (radioesc).

Nossa proposta, levando em consideração essa problemática, é discutir a validade do trabalho sistematizado com o gênero exposição oral com professores e estudantes da modalidade EJA, de um modo geral e do ensino médio, especificamente, buscando um trabalho contextualizado que, implicando o aprimoramento da fala formal em sala de aula, possibilite também um desempenho satisfatório com a EO no ambiente discursivo radiofônico escolar, caso a escola desenvolva um projeto de radioesc. Nesse sentido, foi elaborada e testada uma sequência didática (SD) para a apropriação do gênero exposição oral em sala de aula, com possibilidade de adaptação para um trabalho com o gênero exposição oral radiofônica escolar, conforme descrito na seção quatro. Em outras palavras, o trabalho da EO é desenvolvido sempre como atividade de linguagem significativa, com oradores-locutores reais falando para ouvintes reais (BRONCKART, 1999) e subsidiado por uma proposta metodológica de ensino, nesse caso a SD.

$\mathrm{O}$ artigo está organizado de modo a tematizar a exposição oral ao mesmo tempo como uma atividade de linguagem (ação coletiva) e como um gênero de texto (ação individual). Na seção dois, apresentaremos nossa visão da EO como um gênero de texto. Na seção três, discorremos sobre a inserção da $\mathrm{EO}$ nos programas e quadros de uma rádio escolar. Na quarta seção 
apresentamos alguns subsídios para a elaboração de uma SD para a apropriação desse gênero e no tópico a seguir discutimos a experiência da $\mathrm{EO}$ em duas turmas de EJA - ensino médio de uma escola pública de Caxias do Sul. Ainda nessa seção discutimos a experiência com a SD da exposição oral em duas turmas de EJA - ensino médio de uma escola pública de Caxias do Sul. Na seção seguinte apresentamos algumas considerações finais sobre o trabalho.

\section{A exposição oral (escolar) como um gênero de texto}

Embora a exposição oral seja um gênero utilizado por professores de diferentes disciplinas, principalmente, como forma de avaliação, por intermédio de apresentação de trabalhos ou seminários, ${ }^{1}$ não é, na maioria das vezes, concebida como atividade de ensino explorada pelos professores de Língua Portuguesa. Como resultado dessa falta de planejamento e de sistematização de atividades relacionadas à $\mathrm{EO}$, os estudantes quase sempre demonstram muita dificuldade em relação a esse gênero de texto.

Sabendo da importância de proporcionar, na escola, atividades orais que oportunizem aos estudantes a apropriação de recursos linguísticos e interativos inerentes às práticas orais e considerando que a $\mathrm{EO}$ pode ser uma eficaz ferramenta para a ensinagem de conteúdos conceituais, procedimentais e atitudinais da Língua Portuguesa, neste artigo discutimos um modo sistematizado possível de ensinagem desse gênero em sala de aula, levando também em consideração a possibilidade de inseri-lo no conjunto de gêneros que podem ser trabalhados na implantação / implementação de uma rádio escolar, tais como notícia radiofônica, comentário radiofônico, entre outros.

O termo Exposição Oral pode ser empregado para representar uma noção ampla de ação de linguagem na pauta da oralidade, que pode ser materializada por uma série de gêneros textuais diferentes. De acordo com o contexto, ambiente sociodiscursivo da interação (universidade, escola, empresa, igreja, mídia etc.), a EO assume características funcionais e estruturais de um determinado gênero de texto. Empregado com esse sentido, entende-se a EO como um termo guarda-chuva genérico para denominar seminários, conferências, comentários midiáticos em rádio e tevê, sermões, comunicações em congressos, apresentação de trabalhos na escola, entre outros.

\footnotetext{
${ }^{1}$ Ler Goulart (2005) sobre práticas orais na escola, tese de doutorado em que a autora discorre especialmente sobre o modo como é tratado o gênero seminário em sala de aula.
} 
No âmbito escolar, a EO assume mais comumente uma conotação específica de fala formal para expor algum tema de domínio do orador-locutor (fazer a audiência saber mais sobre esse tema). Schneuwly e Dolz (2004) definem EO como:

Um gênero textual público, relativamente formal e específico, no qual um expositor especialista dirige-se a um auditório, de maneira (explicitamente) estruturada, para lhe transmitir informações, descrever-lhe ou the explicar alguma coisa (p. 218).

Neste artigo, consideramos a EO também como uma ação de linguagem em que o estudante pode exercitar a sua verve crítica, defender seus pontos de vista (fazer a audiência saber a opinião do orador-locutor sobre algum tema). Esse trabalho possibilita o aprimoramento das atitudes discursivas da ordem do expor e do argumentar, já que o estudante toma o papel de especialista do que vai expor ou de crítico de um determinado tema controverso.

É importante frisar que o estudante, para obter um bom desempenho no gênero $\mathrm{EO}$, ciente de que esse gênero pertence à pauta da oralidade formal, precisa cultivar algumas habilidades da pauta da escrita, como o planejamento e a organização do que vai ser dito, por intermédio, por exemplo, da elaboração de roteiros, da confecção de slides de apresentação para ilustrar sua fala, da produção de esquemas, resumos, do registro da locução em uma lauda de programa radiofônico, entre outros.

Assim, na escola, em diferentes níveis de complexidade: séries iniciais e finais do ensino fundamental, no ensino médio e também na modalidade EJA, a prática da $\mathrm{EO}$ pode ser considerada uma importante ferramenta para o desenvolvimento da competência discursiva dos estudantes, tanto na oralidade quanto na escrita, em diferentes situações de comunicação. Quando a atividade de linguagem se dá no âmbito da sala de aula, estamos denominando a ação de linguagem como EO em sala de aula e quando a atividade de linguagem ocorre no âmbito da produção de um programa radiofônico na escola, denominamos a ação de linguagem de $E O$ radiofônica escolar.

\section{A exposição oral radiofônica escolar}

A EO radiofônica escolar é um gênero de texto em que predominam as atitudes discursivas do expor e / ou do argumentar. Alguns quadros de programas de rádio escolar, tais como Você Sabia?, Comentário, Editorial, 
Opinião ou Saiba Mais, podem ser materializados por meio de uma EO radiofônica. ${ }^{2}$

Algumas características básicas diferenciam a EO em sala de aula da EO radiofônica escolar.

No primeiro caso, o estudante assume o papel de orador, conta com a presença da audiência e pode lançar mão de recursos visuais e se comunicar com gestos, olhares, corpo; sente o clima de receptividade de sua fala, podendo adaptá-la ou modalizá-la durante a exposição.

No segundo caso, em que o ouvinte de um programa de rádio não está presente fisicamente e o estudante não o vê, assume-se o papel de locutor, e o estudante precisa organizar sua fala com maior grau de objetividade e clareza, para que a interação locutor-ouvinte seja bem-sucedida.

Em ambos os casos é necessário saber usar os recursos de amplificação da voz, decidindo pelo uso ou não de um microfone. Se a fala é presencial e se a EO é feita em uma sala pequena, o orador poderá dispensar o uso de equipamento, mas, no caso de uma $\mathrm{EO}$ radiofônica, saber usar o recurso tecnológico de amplificação da voz (microfone) para a gravação ou transmissão radiofônica ao vivo é indispensável ao locutor.

Conhecer as peculiaridades dessas diferentes ações de linguagem, de acordo com as diferentes situações de produção e recepção é tarefa para os professores coordenadores dos trabalhos de ensinagem dos gêneros orais em foco. Pensando nisso, elegemos a proposta de elaboração de uma sequência didática $(\mathrm{SD})^{3}$ como estratégia para sistematizar o trabalho de apropriação dos gêneros $\mathrm{EO}$ em sala de aula e EO radiofônica escolar, seja para o estudante atuar como orador, em sala de aula, diante de uma audiência presente, seja para atuar como locutor na produção de um programa da rádio de sua escola, gravando ou falando ao vivo para um quadro de um programa radiofônico.

\footnotetext{
${ }^{2}$ Ver Baltar et al. (2009) Rádio Escolar: letramentos e gêneros textuais, obra que relata experiências de implantação de rádios escolares em escolas públicas - ensino fundamental e EJA - da região do entorno da Universidade de Caxias do Sul, RS. ${ }^{3}$ Recomendamos a leitura de Schneuwly e Dolz (2004), obra traduzida e organizada por Roxane Rojo e Glaís Cordeiro, com o título de Gêneros Orais e Escritos na Escola, que reúne artigos, conferências, capítulos de livro, textos publicados em documentos oficiais etc. de pesquisadores genebrinos que atuam no Groupe Romande de Recherche du Français Enseigné (GRAFE), liderado por Bernard Schneuwly.
} 


\section{Subsídios para uma proposta de SD para o gênero exposição oral ${ }^{4}$}

Propomos neste trabalho, o estudo sistematizado da EO em duas etapas, primeiramente com a EO em sala de aula e, em seguida, com a EO radiofônica escolar, trabalhando as peculiaridades dessas ações de linguagem, de acordo com as diferentes situaçõos de produção e recepção em que se apresentam.

Para realizar uma EO em sala de aula, os estudantes pesquisam sobre o assunto, elaboram um roteiro e, a partir disso, desenvolvem o texto oralmente. Posteriormente, para um programa de uma Rádio escolar (Radioesc), o estudante utiliza-se do roteiro já produzido e reelabora seu texto, dessa vez escrito, levando em consideração o novo ambiente discursivo. Fica ainda a possibilidade de se trabalhar a EO e a EO radiofônica separadamente, já que são situações de comunicação distintas.

Para a EO presencial, é essencial instrumentalizar o estudante para que ele seja capaz de explorar recursos visuais e de expressão corporal, modalizando seu texto conforme a aceitação da audiência.

Já no caso da EO radiofônica, não contando com esses recursos, o estudante deverá reescrever seu texto, fazendo-o mais sucinto e objetivo, registrando sua fala na lauda do programa, como um texto de apoio para a locução, em que os sinais de pontuação são substituídos por sinais indicativos de pausas: breves ( / ) e longas ( // ). Para o sucesso da locução, é aconselhável trabalhar algumas estratégias, tais como, técnica de respiração, controle das pausas, uso adequado do microfone e, principalmente, repetir várias vezes o texto em voz alta para naturalizar a locução, visando transpor a pauta da mera leitura.

Apresentamos a seguir alguns apontamentos para subsidiar uma SD para EO. Nossa proposta desenvolve-se em treze encontros, sendo três deles reservados à adaptação da $\mathrm{EO}$ em sala de aula para o ambiente radiofônico.

\footnotetext{
${ }^{4}$ A base deste trabalho foi uma experiência em sala de aula em que estudantes da EJA / Ensino Médio produziram uma EO falando sobre suas profissões. O trabalho foi desenvolvido por uma professora de educação básica, bolsista do projeto de pesquisa-ação intitulado Mídia \& Escola: letramentos e Gêneros textuais.
} 


\section{$1^{\circ}$ ENCONTRO}

I. Apresentação da situação inicial de produção, abordando as principais características do gênero, em que ambiente discursivo ele acontece, o papel de especialista do expositor, o aspecto tripolar da EO: expositor - tema - público, os gêneros que lhe são aparentados como seminário, comunicaçáo em congresso, palestra, comentário radiofônico, etc.

II. Análise dessas características a partir da audição de um exemplo gravado.

\section{$2^{\circ}$ ENCONTRO}

I. Apresentação da estrutura prototípica do gênero, ${ }^{5}$ a partir da escuta de uma segunda EO.

II. Construção, com os estudantes, do conceito e da caracterização do gênero, baseando-se nas observações feitas.

\section{$3^{\circ}$ ENCONTRO - Produção inicial}

I. Definição de temas e primeira produção.

II. Avaliação da primeira produção para definir o que deve ser aprimorado.

\section{$4^{\circ}$ ENCONTRO - Trabalhando estratégias}

I. Apresentação das principais etapas para a preparação de uma exposição oral. Propomos as seguintes: ${ }^{6}$

- definir o objetivo;

- definir o tempo;

- definir o público;

- estruturar a mensagem;

- revisar o conteúdo;

- treinar em frente ao espelho.

II. Definição do tema que será abordado na produção final, quanto tempo cada estudante irá dispor e marcação da data do início das apresentaçôes.

\footnotetext{
${ }^{5}$ Sugerimos a estrutura apresentada em Schneuwly e Dolz (2004, p. 220-221).

${ }^{6}$ Adaptado da proposta de organização de palestra de MARCON (1992, p. 25-81)
} 


\section{$5^{\circ}$ ENCONTRO - Trabalhando técnicas vocais}

I. Abordagem da importância do tom de voz e do ritmo da fala para colaborar com a compreensão da mensagem.

II. Desenvolvimento de técnicas vocais através de músicas e trava-línguas.

\section{$6^{\circ}$ ENCONTRO - Trabalhando pausas e entonação}

I. Exercício de leitura, em duplas, em que um lê e o outro marca as pausas com barras: simples $(/)$ para pausas curtas e duplas $(/ /)$ para pausas longas. Feito isso, compara-se as pausas com a pontuação do texto.

II. Treino de pausas em diferentes textos.

III. Exercício de entonação: assertiva, interrogativa e exclamativa.

\section{$7^{\circ}$ ENCONTRO - Trabalhando expressão corporal}

I. Explicação e exemplificação de como a postura, a gesticulação e o olhar colaboram para o transporte da mensagem do orador ao público.

\section{$8^{\circ}$ ENCONTRO - Trabalhando o roteiro}

I. Exposição da importância de preparar um roteiro escrito e descrição de como este deve ser preparado.

II. Produção de roteiros de EO a partir de textos de outros gêneros (uma reportagem, por exemplo).

$9^{\circ}$ e $10^{\circ}$ ENCONTRO - Apresentação / avaliação

I. Apresentação da produção final (3 a 7 min para cada estudante).

II. Avaliação das exposições por meio de instrumento previamente preparado pelo professor.

$11^{\circ}$ ENCONTRO - Socialização dos resultados da avaliação: trabalhando os problemas da primeira produção

I. O professor expõe quais foram os problemas mais frequentes constatados na avaliação das exposições.

II. Os estudantes, instigados pelo professor, propõem possíveis soluções para as deficiências apontadas.

III. Cada estudante recebe um breve relatório do que seria necessário aprimorar em sua exposição oral (tom de voz, ritmo, estrutura da exposição, 
gesticulação, etc.), acompanhado de sugestôes para sanar essas eventuais dificuldades na próxima atividade de linguagem. ${ }^{7}$

$12^{\circ}$ ENCONTRO - Transposição para o ambiente radiofônico - A exposição oral radiofônica

1. Debate com os estudantes a respeito das semelhanças e diferenças de uma exposição oral em que o público está presente e uma exposição oral radiofônica.

2. Produção do texto da EO, baseando-se nos roteiros preparados, na própria exposição (no caso de haver uma gravação) e nas observações feitas acerca da diferença entre EO e EO radiofônica escolar. É importante que o texto já seja escrito utilizando-se de barras para as pausas: ( / ) uma barra (pausa breve), (// ) duas barras (pausa longa).

\section{$13^{\circ}$ ENCONTRO - Ajustes na lauda - ensaio de locução - gravação}

I. Em duplas, os estudantes ensaiam a locução do texto escrito na lauda e, com ajuda do colega, verificam as pausas, a entonação e a pronúncia das palavras.

II. Depois de um último treino, dessa vez com o microfone, os estudantes realizam a gravação da $\mathrm{EO}$.

III. Após a gravação, os estudantes analisam a produção, discutem e retificam eventuais problemas (no âmbito da escrita ou da oralidade) e regravam a produção final.

\section{A EO nas turmas T8A e T8B da Educação de Jovens e Adultos da Escola Evaristo de Antoni}

A Escola Estadual de Ensino Médio Evaristo de Antoni situa-se na zona central de Caxias do Sul e atende a aproximadamente 1.800 alunos nos turnos manhã, tarde e noite. Desse total, 150 alunos pertencem à modalidade EJA - Ensino Médio, que é oferecida há quatro anos na instituição. Essa escola é uma das poucas escolas públicas que ainda oferece essa modalidade de ensino na cidade e, dessa forma, recebe estudantes de várias regiōes do município, com realidades e objetivos diversos.

${ }^{7}$ Esse relatório deve ser preparado previamente pelo professor e baseado nas constataçôes acerca da avaliação dos colegas, do professor, e dos próprios oradores / locutores da exposição oral. 
A proposta pedagógica da escola para a Educação de Jovens e Adultos foi reelaborada há dois anos e contou com a participação de professores e da direção em reuniōes semanais, e de alunos, por meio das respostas aos questionários aplicados. O objetivo da proposta é de trabalhar com uma abordagem sociointeracionista, principalmente por meio de projetos interdisciplinares elaborados em reunióes pedagógicas.

Nesse contexto, elaboramos e aplicamos uma SD de ensinagem do gênero EO, no período de abril a junho de 2009, nas turmas T8A e T8B, da totalidade 8 da EJA, que corresponde, aproximadamente, à segunda metade do primeiro ano do EM regular.

Em pesquisa realizada com os estudantes envolvidos na aplicação dessa SD sobre os motivos que os levaram a retomar os estudos, $44 \%$ desses estudantes responderam que procuravam condições melhores de emprego, $33 \%$ estão estudando por exigência do trabalho, e 23\% afirmam que a razão maior é a realização pessoal. Em observaçôes escritas por esses estudantes, notase que o interesse deles está mais voltado para o que se pode aprender na escola do que apenas para o certificado de conclusão.

Dos 50 estudantes entrevistados, 27 afirmam ter vínculo empregatício, 10 trabalham sem a carteira assinada, 7 senhoras se intitulam donas de casa e 6 estudantes estão à procura de emprego. Embora grande parte desses estudantes já esteja inserida no mercado de trabalho, uma minoria está realizada profissionalmente, pois muitos estão insatisfeitos com sua condição profissional, apresentando baixa autoestima e dificuldades de inserção social. Nesses casos, o retorno aos estudos é visto como uma oportunidade de ascensão social e profissional.

Desse modo, o professor de Língua Portuguesa, assumindo posição de agente de letramento, ${ }^{8}$ pode exercer um papel muito importante no desenvolvimento desses estudantes, planejando e executando com eles atividades de linguagem significativas que aprimorem suas competências discursivas, para que possam interagir com maior autonomia nos diferentes ambientes discursivos da sociedade. Assim, a aplicação de uma SD para a apropriação do gênero exposição oral foi considerada como um instrumento didático-pedagógico para oportunizar os envolvidos a apropriarem-se de recursos linguísticos e discursivos inerentes à prática social de falar em público.

\footnotetext{
${ }^{8}$ A expressão agente de letramento, postulada por Kleiman (2005), define o professor ou outro agente como um mediador de práticas sociais, situadas no mundo letrado, pelas quais os estudantes passam ao longo de seu processo de letramento.
} 
Antes de iniciar o trabalho com a SD, para que o trabalho atendesse às necessidades desse grupo, foi aplicado um questionário verificando a experiência dos estudantes com gêneros orais formais. Por meio desse instrumento, foi possível perceber que a maior parte dos estudantes nunca havia feito uma exposição oral e que sua representação sobre aprendizagem e uso adequado da língua era restrita à escrita. A partir dessa constatação definimos a necessidade de destacar a importância da modalidade oral da língua, expondo os objetivos do trabalho.

Feito isso, oportunizamos o contato com o gênero por meio de gravaçóes de vídeo e de áudio de $\mathrm{EO}$, a fim de discutir as principais características do gênero.

Após isso, a realização de uma produção inicial de uma EO com tema livre possibilitou, além do diagnóstico do que deveria ser aprimorado, que os estudantes percebessem que apresentar um trabalho para os colegas, expondose à avaliação deles não era algo intransponível e que eles eram capazes de fazer isso. As primeiras produções já apontaram uma preparação antes da apresentação. Embora um pouco nervosos, os estudantes se saíram bem. A partir da discussão entre autores (oradores / locutores) da EO, colegas e professora foi possível desenvolver certo grau de consciência de como deveria ser uma EO.

Na sequência didática, o gênero foi trabalhado sob diferentes perspectivas: da expressão oral (dicção, entonação, pausas), da expressão corporal (gesto, olhar, posição de braços, mãos) e da preparação do roteiro escrito. Isso permitiu que a SD não se tornasse repetitiva e desestimulante e fez com que os envolvidos participassem de todas as atividades com empenho e entusiasmo.

A primeira etapa da SD culminou com a realização de uma $\mathrm{EO}$ que, conforme o combinado com a turma, desde o princípio dos trabalhos com o gênero, teria como tema as características específicas de sua profissão, ficando como opção, para quem não trabalhasse, falar de uma profissão que gostariam de exercer. Isso contribuiu para que os estudantes se posicionassem realmente como especialistas do assunto apresentado, colaborando para o aspecto interacional da exposição, pois apresentavam um assunto que era do domínio do orador, mas não da audiência.

As apresentações finais surpreenderam a todos positivamente, já que os oradores demonstraram bom desempenho e desenvoltura com o gênero. A atividade de linguagem contribuiu para ampliação do conhecimento de mundo dos estudantes envolvidos, visto que saber sobre as profissões dos colegas possibilitou que conhecessem mais uns aos outros como indivíduos, já que, além de estudantes, são profissionais de diferentes áreas. Em suma, a 
experiência apresentou resultados significativos quanto à desinibição e ao desenvolvimento da expressão oral dos sujeitos envolvidos, além do aprimoramento de seu texto escrito (já que houve produção do roteiro da $\mathrm{EO}$ ), colaborando também para o entrosamento e respeito mútuo da turma, fazendo com que os estudantes se sentissem valorizados como pessoas e como profissionais.

A seguir, apresentamos um exemplo transcrito de exposição oral, resultado dessa experiência, e, logo depois, sua transposição para o ambiente discursivo radiofônico. No primeiro texto, temos a transcrição de uma gravação de uma EO feita em sala de aula, em que o estudante fala, com a ajuda de fotografias, durante aproximadamente cinco minutos, a respeito de sua vivência como metalúrgico. Essa atividade foi realizada por toda a turma que, antes da realização da $\mathrm{EO}$, apresentava um roteiro que era discutido e ajustado com o auxílio da professora. No segundo texto, apresentamos a transposição desse texto para o gênero exposição oral radiofônica escolar, produção feita a partir da discussão das diferenças entre a EO feita em sala de aula e a radiofônica escolar (como proposto na SD apresentada no item 4, Subsidios para uma proposat de SD para o gênero exposição oral), reduzindo o tempo de locução para 2 minutos.

\section{Texto 1}

Boa noite // estou aqui pra falar da minha profissão // Sou metalúrgico há dois anos / e trabalho numa empresa que fabrica rodas pro segmento agrícola // Eu trabalho como operador de conformadora / e minha missão é transformar peças de aço em formato de cubo em rodas // Este processo é chamado conformação / porque dá às rodas as medidas desejadas // Eu trouxe umas fotos // Esta é a máquina que eu trabalho (mostra uma foto dele ao lado da máquina e depois passa para os colegas olharem) // E este sou eu (risos) // Foi um colega que tirou a foto // Esta foto é da roda antes de ser conformada (mostra outra fotografia) e esta aqui é a roda depois de ser conformada // Esta outra é da roda pronta / depois de passar por outros processos // É um trabalho que exige muita atenção / porque se a roda for conformada fora dos padrões / ela vira sucata e atrasa todo o processo de produção // como aqui nesta foto / são rodas que não deram certo porque a máquina estava mal ajustada // Bom / Pra trabalhar como operador de conformadora / é preciso ter cursos de leitura e interpretação de desenho e metrologia // Também é preciso ter ensino médio completo/ e é por isso que estou fazendo EJA // Mas na verdade / o que dá 
segurança pra desempenhar um bom trabalho é a prática e o comprometimento com o resultado final // E pra que o resultado seja positivo / também é importante o trabalho em equipe dos funcionários do setor // Sempre que é admitido um novo funcionário pro setor / procuro falar pra ele sobre isso / sobre o trabalho em equipe // quanto à remuneração / acho que está de acordo com a função / apesar de que / com a crise / a situação complicou um pouco // Pra que não houvesse demissões / por enquanto / não trabalhamos nas segundas feiras / daí diminuiu um pouco o salário // mas em compensação / temos mais um dia para descansar / e isso até que é bom né // Pra encerrar / quero dizer que gosto muito do que faço / porque na função que desempenho / é possível ver / visualizar os resultados do meu trabalho // $\mathrm{E}$ acredito que / pra estar feliz como profissional é essencial gostar do que faz. (407 palavras)

\section{Texto 2}

Boa noite // Meu nome é Fernando Souza / sou aluno da turma T10 A e estou aqui para falar da minha profissão // Sou metalúrgico há dois anos / e trabalho em uma empresa que fabrica rodas para o segmento agrícola // Eu trabalho como operador de conformadora / e minha missão é transformar peças de aço em formato de cubo em rodas // Este processo é chamado conformação / porque dá às rodas as medidas desejadas // É um trabalho que exige muita atenção / pois se a roda for conformada fora dos padróes / ela vira sucata e atrasa todo o processo de produção // Para trabalhar como operador de conformadora / é preciso ter cursos de leitura e interpretação de desenho e metrologia // Também é preciso ter ensino médio completo / e é por isso que estou cursando EJA // Para realizar um bom trabalho em minha profissão é necessário comprometimento com o resultado final // além disso / é importante o trabalho em equipe dos funcionários do setor // Para encerrar / quero dizer que gosto muito do que faço / porque na função que desempenho / é possível visualizar os resultados do meu trabalho // E acredito que / para estar realizado como profissional e como pessoa / é essencial gostar do que faz. (221 palavras)

\section{Análise das atividades de linguagem envolvendo a EO em sala de aula e a EO radiofônica escolar}

Propomos neste trabalho o estudo sistematizado da EO em duas etapas, primeiramente com a EO em sala de aula e, em seguida, com a EO radiofônica escolar, trabalhando as peculiaridades dessas açóes de linguagem, de acordo com as diferentes situações de produção e recepção em que se apresentam. 
Para realizar uma EO em sala de aula, os estudantes pesquisam sobre o assunto, elaboram um roteiro e, a partir disso, desenvolvem o texto oralmente. Posteriormente, para um programa de uma Radioesc, o estudante utiliza-se do roteiro já produzido e reelabora seu texto, dessa vez escrito, levando em consideração o novo ambiente discursivo. Fica ainda a possibilidade de se trabalhar a EO e a EO radiofônica separadamente, já que são situações de comunicação distintas.

Para a EO presencial, é essencial instrumentalizar o estudante para que ele seja capaz de explorar recursos visuais e de expressão corporal, modalizando seu texto conforme a aceitação da audiência.

Já no caso da EO radiofônica, não contando com esses recursos, o estudante deverá reescrever seu texto, fazendo-o mais sucinto e objetivo. A seguir ele registra sua fala na lauda do programa, como um texto de apoio para a locução, em que os sinais de pontuação são substituídos por sinais indicativos de pausas: breves ( / ) e longas ( // ). Para o sucesso da locução, é aconselhável trabalhar algumas estratégias, tais como, técnica de respiração, controle das pausas, uso adequado de microfone e, principalmente, repetir várias vezes o texto em voz alta para naturalizar a locução, visando transpor a pauta da mera leitura.

\section{Algumas considerações finais}

Embora a EO em sala de aula seja um gênero utilizado principalmente como forma de avaliação por professores de diferentes disciplinas, o trabalho não é, na maioria das vezes, concebido como atividade significativa de linguagem textual e discursiva. Considerando esse problema, discutimos aqui a validade de um trabalho contextualizado e sistematizado que, além de desenvolver a fala formal em sala de aula, possibilite um desempenho satisfatório com a EO em ambientes discursivos diversos, de acordo com as redes de pertencimento dos sujeitos envolvidos nessa atividade, especialmente o seu local de trabalho. $\mathrm{O}$ ambiente discursivo midiático-radiofônico escolar, quando existe na escola, também pode acolher esse tipo de atividade, criando espaços em que oradores-locutores reais possam interagir com ouvintes reais e responsivos.

A experiência com essa atividade na EJA revelou resultados significativos de desempenho pessoal e coletivo dos sujeitos envolvidos, no que tange ao aprimoramento de seus textos-discursos, tanto na pauta da oralidade (na execução das falas formais em sala de aula) quanto na pauta da escrita (já que 
houve produção de roteiros). Algumas questões de interação de sala de aula e de comportamento também vieram à baila e devem ser destacadas, principalmente no contexto EJA, tais como, a desinibição, o aumento da autoestima, maior entrosamento e respeito mútuo, fazendo com que os estudantes se sentissem valorizados como pessoas e como profissionais (já que as EO tiveram como tema as peculiaridades de suas profissōes).

Em síntese, com este trabalho, estamos chamando a atenção de professores de Língua Portuguesa para a necessidade de criação de espaços viáveis em sala de aula para o desenvolvimento de atividades orais que oportunizem aos estudantes o aprimoramento de seus recursos textuais-discursivos, a serviço da interação social em práticas orais significativas na escola.

Uma ferramenta que tem se mostrado eficaz para o trabalho sistematizado de apropriação de gêneros na escola (certamente não é a única) é a sequência didática, como já foi comprovado por inúmeros estudos, tais como Schneuwly (1997), Schneuwly; Dolz (2004) Baltar et al. (2008b), Baltar et al. (2009).

A título de subsídio apresentamos neste trabalho uma SD possível para a EO em sala de aula, que pode ser adaptada para o ambiente discursivo radiofônico escolar e aplicada em outros contextos, desde que se façam as adaptações necessárias para que a atividade de linguagem seja sempre significativa para todos os envolvidos, ampliando sua compreensão sobre o uso e funcionamento da língua-linguagem, modalidades oral e escrita, nas diferentes práticas letradas da sociedade.

\section{Referências}

BALTAR, M. Rádio escolar: letramentos e gêneros textuais. Caxias do Sul: EDUCS, 2009.

BALTAR, M. Competência discursiva e gêneros textuais: uma experiência com o jornal em sala de aula. 2. ed. Caxias do Sul: EDUCS, 2006.

BALTAR, M. O conceito de tipos de discurso e sua relação com outros conceitos do ISD. In: GUIMARÃES, A. M. M.; MACHADO, A. R.; COUTINHO, A. Interacionismo Sociodiscursivo: questôes epistemológicas e metodológicas. Campinas-SP: Mercado de Letras, 2007.

BALTAR, M. Letramento radiofônico na escola. Linguagem em (dis)curso: letramento e formação de professores. v. 8, n. 3, p. 563-580, 2008.

BALTAR, M. et al. Rádio Escolar uma ferramenta de interação sociodiscursiva. Revista Brasileira de Linguistica Aplicada, v. 8, p. 185-210, 2008 a. 
BALTAR, M. Notícia radiofônica: apropriação de um gênero de texto na implantação de rádios escolares. Signo, v. 33, n. 55, p. 96-116, 2008 b.

BALTAR, M. Rádio escolar: letramentos e gêneros textuais. Caxias do Sul: EDUCS, 2009.

BRONCKART, J-P. Atividade de linguagem, texto e discurso: por um interacionismo sociodiscursivo. São Paulo: EDUC, 1999.

GOULART, Cláudia. As Práticas orais na escola: o seminário como objeto de ensino. 2005. Tese (Doutorado) - IEL-Unicamp - Campinas, SP, 2005.

KATO, M. A. No Mundo da Escrita: uma perspectiva psicolinguística. 2. ed. São Paulo: Ática, 1987.

KLEIMAN, A. Processos identitários na formação profissional: o professor como agente de letramento. In: CORRÊA, M. (Org.). Ensino de línguas: letramento e representaçōes. Campinas: Mercado de Letras, 2005.

KOCH, I. G. V. A inter-ação pela linguagem. São Paulo: Contexto, 1993.

MARCON, Leocides. Falar em público: desinibição, oratória, dicção. Porto Alegre:CDP, 1992.

MARCUSCHI, L. A. Da fala para a escrita: atividades de retextualização. São Paulo: Cortez, 2005.

SCHNEUWLY, B.; DOLZ, J. Gêneros orais e escritos na escola. Campinas-SP: Mercado de Letras, 2004.

SCHNEUWLY, B. O ensino da língua oral na escola. Enjeux - revue de didactique du français, Universidade de Genebra, p. 130-158, 1997.

Recebido em novembro de 2009. Aprovado em janeiro de 2010. 